\title{
Optimal product/customer mix selection as a strategic tool for cross-functional integration
}

\author{
João Neiva de Figueiredo \\ Saint Joseph's University \\ jneiva@sju.edu \\ Sergio Fernando Mayerle \\ Universidade Federal de Santa Catarina \\ mayerle@deps.ufsc.br \\ Felipe Simas Donato \\ Universidade Federal de Santa Catarina \\ felipe.donato@gmail.com
}

\begin{abstract}
Cross-functional integration is a necessity as operations become ever more important for the formulation and implementation of overall company strategy. Despite the abundance of theoretical studies extolling the advisability of smooth intra-company interfacing, the operations strategy literature has not been as prolific regarding tools to increase this desired integration. This paper develops an uncomplicated multi-period analytical model that helps increase coordination of the engineering, purchasing, marketing, and sales areas among themselves and with manufacturing by focusing on the overall company objective of maximizing contribution to profits. The paper begins describing the theoretical underpinnings of production and operations processes as they relate to the strategy of the firm, presents the model, and then expands its scope to include interfaces with other functional areas of the firm. The methodology is based on a two-stage multi-period optimization model for aggregate production planning encompassing component supply management and final assembly. This methodology expands the concept of Sales and Operations Planning (S\&OP) through a linear programming model that uses cost and profit contribution data to select the optimal product and customer mix. The sensitivity of results to costing and pricing data leads to increased cross-functional coordination. An illustrative application improving the medium-term operations strategy of a Brazilian OEM manufacturer is presented.
\end{abstract}

Keywords: aggregate production planning; S\&OP; cross-functional integration; product mix; product/ client mix; linear programming

\section{INTRODUCTION}

Tight linkages between companies' strategic planning processes and factory floor tools are a necessity in today's competitive environment in which close alignment between formulated strategic objectives and functional area initiatives is more than a potent competitive weapon - it is a necessary condition for successful performance in the marketplace. These linkages among the various levels of planning, from the strategic level to the plant-floor scheduling level, including medium-term planning such as Sales and
Operations Planning (S\&OP), are extremely important for consistency of goals and effective execution. Production planning and control systems are necessary for operations management in any manufacturing company not only because they provide the necessary information for raw materials purchasing and short-term production planning, but also because their output provides information that supports marketing and sales initiatives as well as broader strategic decisions, such as capital investments and product development, for example. 
Production planning and control systems have yet another important strategic role, as a support to medium-term planning. Expected sales demand in the ensuing 6 to 24 month period is the first input for medium-term planning, the output of which is the production and inventory plan for the period, which feeds into longer term financial planning. Financial goals such as gross profit, operating income, and free cash flow generation are linked to this planning level. Important decisions, such as the mix of products to be produced, the use of overtime, the safety inventory levels, and investment needs, are linked closely to medium-term planning. These decisions involve efficient integration of operations with other areas of the firm such as engineering and product development, purchasing, marketing, and sales. Therefore the production planning and control systems effectively are tools to promote this increased integration.

Although the academic literature has for decades underlined the importance of the aforementioned linkages between different levels of planning and between different areas of the firm, there is a dearth of specific mathematical tools and methodologies to support them. This paper seeks to fill that gap by proposing, developing and applying an uncomplicated optimization model that does just that. The paper describes a linear programming model to optimize the tradeoffs inherent to the critical variables in the medium-term planning process, developing a viable production plan that maximizes contribution to company profits. An illustration of the analytical model is also provided - its application to the productive process of a Brazilian mechanical manufacturer.

The model described herein is a decision-support methodology in that it is a tool for planners to make informed trade-off decisions regarding productclient mix profiles that maximize the contribution to the firm's profit when capacity is constrained at least periodically. When examining a given period the model looks "ahead" six to twelve periods in a rolling horizon (sliding window) approach. It therefore takes medium-term objectives into account when providing subsidies for short-term decisions and provides a link between the firm's strategic and operational goals including plant-floor scheduling. Because the model can be used to improve pricing and placement decisions through sensitivity analysis of dual variables and other post-optimality analyses, it also represents a tool for marketing as well as manufacturing and can contribute to increased com- munications between these two and other functional areas. The model offers a systemic approach to the problem taking into account a vast array of costs including both regular and overtime labor costs, inventory holding costs, and component sourcing costs, for example.

The paper offers several contributions to the literature. First, it introduces a practical tool that has been developed with the specific intention of narrowing gaps between long-term company goals and shopfloor scheduling short-term objectives, and between manufacturing and pricing decisions. Second, it describes a mathematical optimization model in which the objective is to maximize contribution to profits rather than the usual cost minimization procedures and therefore is not only more closely aligned with overall company objectives, but also more helpful for inter-functional coordination. Third, it develops a framework for analyzing different product/client pairs and describes how this input can be helpful for the strategic planning process and for increased integration among different areas of the firm. In this vein the paper identifies specific post-optimality sensitivity analyses that can be very useful to understand implications of certain policies. Lastly, it provides an illustration of the methodology by applying it to the case of an OEM supplier in Brazil. Although these elements have been discussed individually in the literature, they have not yet been examined jointly together with an illustrative application which not only provides insights to academic researchers, but also offers guidance to practitioners.

This section introduces the paper. Section 2 describes production planning and control systems within the context of a brief literature review. The third section describes the optimization model and presents its mathematical formulation. Section 4 introduces an illustrative application of the model and reports the results obtained. Section 5 offers a discussion of these results and examines the model's contributions to increased inter-functional coordination through the analysis of changes in customer and product mix identified by the model. Section 6 concludes.

\section{PROBLEM POSITIONING AND LITERATURE REVIEW}

This section provides an overview of the various stages of production planning and control systems and positions the methodology described herein within the academic literature examining connec- 
tions with other planning levels as well as linkages with other functional areas of the firm.

\subsection{Operations Strategy and inter-functional coor- dination}

Following Swamidass (1986) and Anderson et al. (1989), Boyer et al. (2005) defined operations strategy as "decisions and plans involving the developing, positioning, and aligning of managerial policies and needed resources so that they are consistent with the overall business strategy". The central aspect of the early literature on operations strategy was to ensure two-way linkages between manufacturing decisions and overall business strategic direction, i.e., not only would operations decisions need to be consistent with overall business strategy, but also operational strengths and weaknesses became inputs for company strategic planning. Hayes and Wheelwright (1984) and Hayes et al. (1988) articulated the importance of production and operations for overall business strategy and emphasized the linkages between manufacturing and other areas of the firm. A necessary condition for a holistic approach to manufacturing strategy is inter-functional integration as has been described extensively in the literature on product development, such as Langerak and Hultink (2005).

The immediate consequence was that increased interaction among company functions became desirable and academics began investigating the behavioral, systemic, and informational aspects of cross-functional efficiency. There is an extensive organizational theory literature on inter-functional coordination, but it is focused mostly on intra-firm behavioral frameworks. Much less has been written about actual processes and tools that can be used to improve cross-departmental communications and effectiveness from the point of view of manufacturing and operations management. The closest has been the series of papers on decision support systems which, very much as this paper, address specific situations, such as Matuyama et al. (2009).

The desirability of integrating marketing and manufacturing as well as the difficulties resulting from occasionally conflicting incentives have also been examined in the literature. Crittenden et al. (1993) noted that inter-functional conflict and unenlightened decisions at the functional level may negatively affect company strategies. They described potential conflict situations between manufactur- ing and marketing and, after listing four facilitating mechanisms, suggested that group decision support systems can greatly facilitate inter-functional coordination. Crittenden and Crittenden (1995) specifically examined the impact of manufacturing and marketing decisions, including customer mix and product mix, on firm profitability. In particular, one of their propositions, that a constrained capacity firm focusing solely on price or cost is at greater risk of losing money than a constrained capacity firm focusing on customer mix, supports the use of the model presented herein as a bridge between manufacturing and marketing functions. Hausman et al. (2002) investigated the interface between those two functions and proposed a model to assess the level of harmony between them finding that emphasis on the function itself and the flow of information have a positive impact. The decision-support model presented herein is an example of a mechanism to facilitate cross-functional information flow and joint inter-functional decision-making, therefore becoming an important instrument for increased intra-firm functional integration.

\subsection{Strategic direction and production planning and control systems}

Production planning and control systems are responsible for materials flow planning and control through manufacturing processes and are tools to support strategic planning at both the tactical and the operational levels. Strategic planning identifies long term company goals through the definition of the main business drivers throughout a time horizon of five to ten years, depending on specific sector characteristics. The production planning and control system is deployed in tactical and operational planning, for the medium and short term. Medium term planning, or S\&OP, covers the 6 to 24 month time horizon at the tactical level and helps translate strategic objectives into operational directives while also helping provide linkages among different functional areas of the firm, such as engineering, manufacturing, marketing, and sales planning.

The strategic importance of manufacturing has been extolled in the academic literature for decades as exemplified by Skinner (1985), Hayes, Wheelwright and Clark (1988), Hayes and Pisano (1996), and more recently by Hayes, Pisano, Upton and Wheelwright (2004). Gianesi (1998) identified managerial benefits in the broader application of S\&OP, such as interdepartmental integration, multi-timeframe decision 
consistency, and the elimination of intra-organizational barriers. Olhager and Rudberg (2002) examined the role of manufacturing planning control systems in supporting the firm's marketing and manufacturing strategies, and focused on the importance of process-specific elements. S\&OP can be helpful in mitigating the Bullwhip Effect, a solution for which was proposed by Warburton (2004). Other instances in which the advantage of S\&OP integration with other levels of planning are of note are the case of uniform guaranteed lead time as investigated by
Rao, Swaminthan, and Zhang (2005), and the case of manufacturing flexibility strategies as developed by Ketokivi (2006). Grimson and Pyke (2007) offered a five-stage framework for helping improve the effectiveness of S\&OP processes with close linkages to overall company strategy. Olhager and Selldin (2007) used a survey-based design to analyze the interrelationships between manufacturing planning and control approaches at different levels and operational performance given market requirements.

Figure 1. Production planning and control system (adapted from Vollmann et al., 1997).

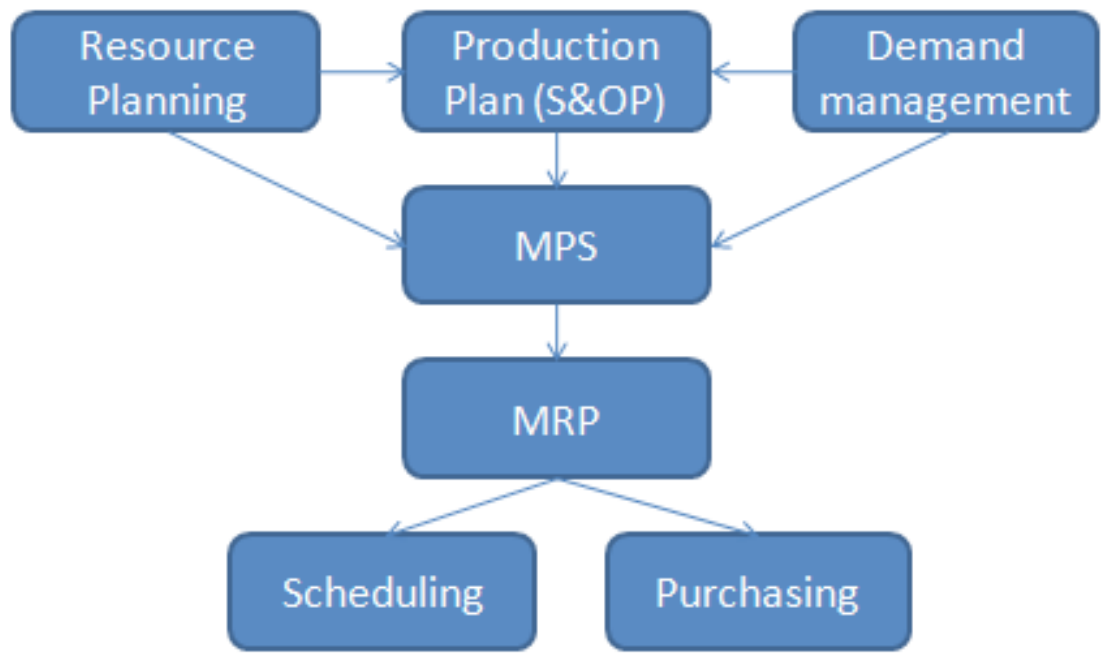

According to Wallace (1999), S\&OP focuses on aggregate volumes and product families. Issues related to product mix, to individual products, and to client orders were to be resolved at the more detailed operational level. The S\&OP process provides the mid-term aggregate operations, sales, and inventory plans, which include both volume and value data. When it includes reliable financial data such as, for example, products' prices and costs, leading to marginal contribution to profits, the S\&OP can act as a tool to substantially improve company results and indeed contribute to product mix and individual product decisions. These plans must also consider relevant constraints in the operations system in order to ensure that the plan is feasible at the operational level. There are various categories of constraints to be considered, including manufacturing bottlenecks, workforce constraints, and supply chain characteristics, among others. Figure 1 sum- marizes the different levels of a production planning and control system and presents the planning process at the tactical and operational levels.

The S\&OP process provides input for the Master Production Schedule (MPS), i.e., short-term planning. In this step, the plan is disaggregated from the broad product family level to the level of each specific SKU. Materials Requirements Planning (MRP) also belongs to the short-term planning phase as it generates the raw materials and component purchase plans. The last step of the Production Planning and Control System is execution (actual production). At this moment, production scheduling is generated and production and purchase orders are issued to the shop floor and to the suppliers.

\subsection{Hierarchical production planning}


The aggregate production plan is executed at the tactical level in a hierarchical planning model - in the flow proposed in Figure 1 the aggregate production plan fits within Sales and Operations Planning and uses inputs from many functional areas of the firm such as purchasing, marketing, engineering, and manufacturing, and also providing outputs to various functional areas such as manufacturing, marketing, sales, and post sales support. It follows from these physical and informational flows that inter-functional coordination is a necessity. According to Axsater (1986), the purpose of the aggregate plan is to ensure that long-term considerations are not ignored when making short-term decisions and to ensure that company-wide objectives are not overridden by functional objectives. In systemic terms, local optima are should not be pursued at the expense of the global optimum. Singhal and Singhal (2007) examined the impact of early work in aggregate production planning on the recent evolution of operations and supply chain management. They considered a broader objective for aggregate production planning as it plays a key role in enterprise resource planning and organizational integration by linking operations with accounting, distribution, finance, human resources management, and marketing. According to Lee and Khumawala (1974), aggregate production planning is related to how the organization will respond to fluctuating demands on its productive system and also how it will determine aggregate production levels, inventory, and work force size. Gianesi (1998) pointed out the impact of the planning process on direct and indirect costs, such as labor and inventory costs, on delivery speed, on delivery reliability, and on flexibility.

The concept of hierarchical production planning was first developed by Hax and Meal (1975), who proposed three aggregation levels: a) items - the lowest aggregation level corresponding to end products delivered to the customers; b) families - groups of items pertaining to a same product type and sharing similar setups; c) product types - groups of families having similar cost structures, manufacturing processes and seasonalities. The top decision level in a hierarchical production planning process focuses on product type decisions. At this level, product mix, inventories, and manufacturing strategies as well as hiring and layoff decisions are reached in each planning period. The product type planning is disaggregated to the family level and further disaggregated to the item level. From an analytical standpoint, each hierarchical level is constrained by the volume of the level immediately above it; so short-term plan feasibility is not jeopardized.

Dempster et al. (1981) suggested two fundamental reasons for using a hierarchical approach: a) to reduce complexity, because aggregating products in families and product type groups simplifies planning; and b) to better cope with uncertainty, because the implicit hierarchy of decisions facilitates aggregate planning. Medium-term decisions, such as hiring and layoffs, can be taken based on an aggregate plan while more focused decisions can be postponed. They also point out that hierarchical planning has a parallel with the organizational structure of most firms. The higher up in the product-hierarchy pyramid, the broader the impact decisions will have on other areas of the organization. Furthermore, because of the interconnectedness among the several layers of decision aggregation across hierarchical levels, any decision will impact other hierarchical levels and other functional areas of the firm.

\subsection{Optimization models}

The first optimization approach for aggregate production planning was developed by Holt, Modigliani and Simon (1956). The authors formulated the problem of defining the aggregate production rate and workforce size in each planning period so demand variations were absorbed and total costs were minimized. Three basic variables were developed to solve the problem: a) the size of the work force by hiring and firing in each period; $b$ ) the production rate with a constant work force level; c) the inventory and backlog level with a constant work force and a constant production rate. Since then there has been a vast body of literature on the topic - a summary of the relevant techniques can be found in Sprague et al. (1990). 
Figure 2. Two-stage production flow (adapted from Bitran et al., 1982).

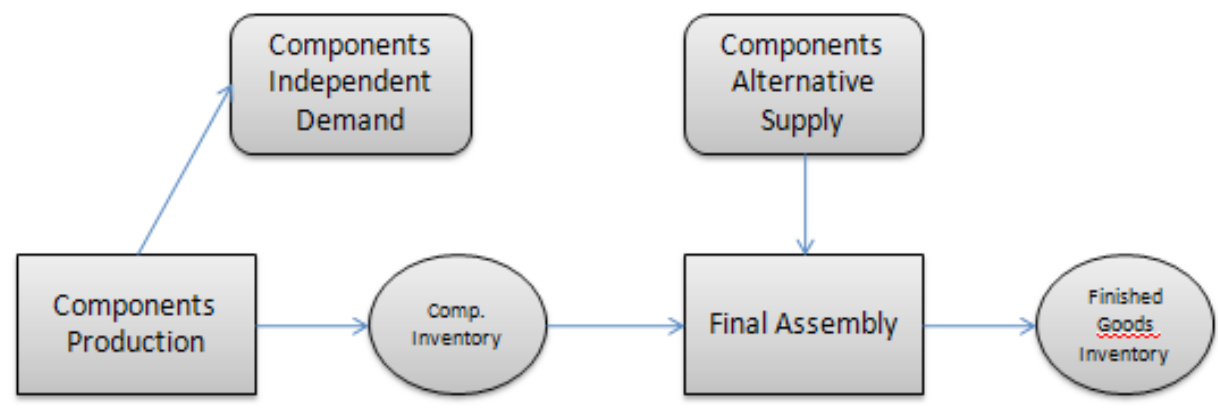

Two publications by Bitran, Haas and Hax (1981, 1982) proposed linear programming models to solve the aggregate production planning problem respectively with a single stage and a two-stage approach at the product type aggregation level. The single stage model formulated the production plan per product type without consideration for pre-assembly component production. The objective was to minimize overall costs, including raw materials costs and inventory costs. The two-stage model differed from this one by assuming the existence of a process to produce components to be used in final assembly. They used two aggregation levels for components: items, i.e., components that are either necessary for assembly of a final product or have independent demand; and item types, i.e., groups of items with similar production costs, unit inventory costs and productivity. Figure 2 shows the production flow in a two-stage system.

The vast majority of the production planning optimization models in the literature is cost minimizing, and therefore do not take into account market considerations such as pricing, product mix, and contribution to profit margins. Özdamar et al. (1998) presented a formulation including subcontracting production capacity, existence of backorders, existence of maximum resource sub-utilization levels, and use of inventory and backorder goals per period. Newman and Kuchta (2004) formulated a mixed integer program to schedule iron ore production over multiple time periods in which the objective function minimized deviations from planned production quantities. Feng, D'Amours and Bouregard (2008) presented an S\&OP modeling approach that integrates cross-functional planning of sales, production, distribution, and procurement, allowing for the central evaluation of its impact before implementation. Multi-criteria approaches whereby an optimal result should include several considerations are also possible. A few such criteria might be: alignment with the market and company guidelines; physical constraints, such as resource capacity levels, product quality levels, and raw material availability; earnings maximization, expressed through financials; and inventory value minimization.

The literature on product mix optimization includes a variety of models but very few consider joint customer/product mix decisions. Generally heuristic or meta-heuristic approaches are used to find solutions for product mix problems, which are an important component of the Theory of Constraints (please see Goldratt, 1988) and these heuristics rely heavily on characteristics of the specific case being examined as illustrated by recent research. Wang et al. (2009) proposed an immune mechanism algorithm approach to maximize throughput in a capacity-constrained resource. Hasuike and Ishii (2009) investigated several production planning problems in which product-mix decisions under random and fuzzy conditions and proposed models for them. Zhang and Tseng (2009) observed that manufacturing in general is moving towards higher product mix and lower volume and incorporated customer flexibility into a proposed product mix flexibility model. Tsoulos and Vasant (2009) proposed an evolutionary optimization technique to solve the product mix selection problem. Nazari-Shirkouhi et al. (2009) proposed a meta-heuristic algorithm which they called the Imperialist Competitive Algorithm to solve the integrated product mix-outsourcing optimization problem. The model proposed in this paper has the added advantage that it obtains the theoretical optimum and is not based on heuristic methods.

\section{MATHEMATICAL FORMULATION}

The methodology presented herein is robust and can be applied to most any manufacturing environment 
with adaptations. The objective is to identify the product/client mix that maximizes contribution to company profits. An effective costing system, good demand forecasting, efficient linkages with other functional areas, and coordination with the longterm plan and the short-term production schedule are essential prerequisites for obtaining maximum benefit from this medium-term strategic analytical tool. The formulation below applies to the particular situation in which clients agree to prices in advance product characteristics, and other supply chain considerations - the same product can be sold to different clients at different prices depending on the characteristics of each contract. Because prices are agreed to in advance, individual product contributions to profit are known. In these circumstances identifying the optimal product/client mix has high strategic importance to the company because it offers subsidies for other areas of the firm, such as the sales force, for example, to act in a profit maximizing and not in a revenue maximizing way.

Use of the model as a planning tool that offers input to production programming decisions is best accomplished through a rolling horizon (sliding window) approach. The model focuses on short-term demand which is already known and therefore should be run in the beginning of each analysis period with data from several (e.g., six to twelve) periods ahead. Production and pricing decisions, however, should be made only for the immediate period (i.e., the model will be run again in the beginning of the next period with updated data). This implies that medium-term trends inform short-term decisions and also allows additional datagathering to occur before the model is again run in the beginning of the subsequent period.

This section defines the variables used by the optimization model and presents the mathematical formulation.

\subsection{Decision variables and parameters}

\subsubsection{Model indexes}

The indexes used in the model are the following:

$t$ - time unit (e.g., week or month);

$p$ - product grouping (at the appropriate planning aggregation level);

$c$-component used in the assembly of the product grouping;

$m$ - assembly line;

$i$ - clients purchasing a product.

\subsubsection{Model parameters}

The model uses several parameters:

$d r m_{m, t}=$ regular hours available in assembly line $m$ in period $t$;

$d h e m_{m, t}=$ overtime hours available in assembly line $m$ in period $t$;

$d r c_{c, t}=$ regular hours available to produce component $c$ in period $t$;

$d h e c_{c, t}=$ overtime hours available to produce component $c$ in period $t$;

$v m_{m, t}=$ hourly production in assembly line $m$ in pe$\operatorname{riod} t$

$v c_{c, t}=$ hourly component production in component cell $c$ in period $t$;

$\operatorname{dispex}_{c, t}=$ availability to buy component $c$ from a supplier in period $t$.

Overtime costs parameters are payroll variable costs and physical resource utilization:

chem $_{m, t}=$ overtime cost in assembly line $m$ in period $t$; chec $_{c, t}=$ overtime cost to produce component $c$ in pe$\operatorname{riod} t$

$\operatorname{cexc} c_{c, t}=$ cost to source component $c$ from an external supplier in period $t$ (under unusual circumstances and only in the very short term this cost may be set artificially high to indicate non-tangible additional costs other than purchase price such as, for example, the extra effort to develop supplier relationships, and the disruption resulting from obtaining additional sourcing alternatives - it is preferable to use market costs).

The inventory holding cost is a function of the inventory holding discount rate (a function of the company's cost of capital) and is used to ensure that the model accurately considers tradeoffs between inventory holding costs and overtime capacity, for example. The firm's discount rate for inventory holding costs is an important component of the firm's inventory policy:

$c e_{p, t}=$ cost of a product $p$ in period $t ;$

$r=$ discount rate used to calculate the inventory holding cost;

$\mathrm{mu}_{i, p, t}=$ unit contribution margin of product $p$, at client $i^{\prime}$ s price in period $t$;

$d_{i, p, t}=$ demand for product $p$, by client $i$, in period $t$. 
The following parameters are meant to ensure feasibility of the production plan, that is, they ensure that there will be available resources to produce the products listed in the plan.

$p m_{p, m}=$ binary parameter linking product $p$ with assembly line $m$ : if it is possible to assemble the product, $p m_{p, m}=1$, otherwise $p m_{p, m}=0$;

$p c_{p, c}=$ quantity of component $c$ assembled in product $p$;

$e i_{p}=$ initial stock volume of product $p$, in units.

\subsubsection{Decision variables}

$X r m_{p, m, t}=$ regular production of product $p$, in assembly line $m$, in period $t$;

$\mathrm{Xhem}_{p, m, t}=$ overtime production of product $p$, in assembly line $m$, in period $t$;
$X r c_{p_{c, c}, t}=$ regular production of component $c$ assembled in product $p$, in period $t$;

Xhec $c_{c, t}=$ overtime production of component $c$, in period $t$;

$\operatorname{Xex} c_{c, t}=$ quantity of outsourced component $c$, in period $t$;

$E_{p, t}=$ units of product $p$ in inventory at the end of a period $t$;

$V_{i, p, t}=$ sales volume of product $p$, to client $i$, in period $t$.

\subsection{Objective function}

The objective function $Z$ to be maximized is the contribution to the profit of the company by adding the unit contribution margins of products forecasted to be sold and subtracting additional product and component overtime production costs and inventory holding costs.

$Z=\sum_{i=1}^{I} \sum_{t=1}^{T} \sum_{p=1}^{P}\left[\boldsymbol{m}_{i, p, t} V_{i, p, t}-\boldsymbol{e}_{p, t} r E_{p, t}-\sum_{m=1}^{M}\left(\operatorname{chem}_{m, t} X_{h e m_{p, m, t}}\right)-\sum_{c=1}^{C}\left(\operatorname{chec}_{c, t} X_{h e c_{c, t}}-\operatorname{cexc}_{c, t} \operatorname{Xexc}_{c, t}\right)\right]$

\subsection{Constraints}

\subsubsection{Inventory conservation equation}

The inventory conservation equation calculates the inventory of product $p$ at the end of period $t$, considering the inventory at the end of the previous period (period $t-1$ ) and the production and sales in period $t$.

if $\mathrm{t}>1$,

$\left.E_{p, t}=E_{p, t-1}+\sum_{m=1}^{M}\left(X r m_{p, m, t}+X h e m_{p, m, t}\right) * m_{p, m}\right)-\sum_{i=1}^{I} V_{i, p, t}, \quad \forall p=1, \ldots, P, \forall t=2, \ldots, T$

if $\mathrm{t}=1$,

$\left.E_{p, t}=E_{p}+\sum_{m=1}^{M}\left(X_{r m} m_{p, m, t}+X h e m_{p, m, t}\right) * m_{p, m}\right)-\sum_{i=1}^{I} V_{i, p, t}, \quad \forall p=1, \ldots, P$

\subsubsection{Assembly line capacity constraints}

Assembly line capacity constraints ensure that allocated volumes in each assembly line $m$ and in each cell producing a given component $c$ conform to production availability in any given period $t$.

$$
\sum_{p=1}^{P}\left(X r m_{p, m, t} m_{p, m}\right)=d r m_{m, t} m_{m, t}, \quad \forall m=1, \ldots, M, \forall t=1, \ldots, T
$$

$\sum_{p=1}^{P}\left(\right.$ Xhem $\left._{p, m, t} m_{p, m}\right) \leq d h e m_{m, t} m_{m, t}, \quad \forall m=1, \ldots, M, \forall t=1, \ldots, T$

\subsubsection{Component production constraints}

Those constraints ensure that production of a given product $p$ in period $t$ is limited to the available capacity to produce each component $c$ in product $p^{\prime} s$ configuration.

$\sum_{p=1}^{P}\left(X r c_{p, c, t} p_{p, c}\right) \leq d r c_{c, t} \boldsymbol{e}_{c, t}, \quad \forall c=1, \ldots, C, \forall t=1, \ldots, T$

$\sum_{p=1}^{P} X h e c_{c, t} p_{p, c} \leq d h e c_{c, t} \boldsymbol{c}_{c, t}, \quad \forall c=1, \ldots, C, \forall t=1, \ldots, T$

$\sum_{p=1}^{P} \operatorname{Xexc}_{c, t} p_{p, c} \leq \operatorname{dispex}_{c, t}, \quad \forall c=1, \ldots, C, \forall t=1, \ldots, T$ 
$\sum_{m=1}^{M}\left[\left(X r m_{p, m, t}+X h e m_{p, m, t}\right) m_{p, m}\right]_{p, c}=X r c_{c, t}+X h e c_{c, t}+X e x c_{c, t}, \quad \forall p=1, \ldots, P, \forall c=1, \ldots, C, \forall t=1, \ldots T$

\subsubsection{Maximum demand constraint}

This equation ensures that the sales of a given product $p$ is limited by the respective forecasted demand in each period $t$.

$$
V_{i, p, t} \leq d_{i, p, t}, \quad \forall i=1, \ldots, I, \forall p=1, \ldots, P, \forall t=1, \ldots T
$$

\subsubsection{Non-negativity constraints}

$\mathrm{Xrm}_{p, m, t^{\prime}}$ Xhem $m_{p, m, t^{\prime}}$ Xhec $\mathrm{c}_{c, t^{\prime}}$ Xhec $c$ e Xrt $\mathrm{Xr}_{c, t^{\prime}} E_{p, t^{\prime}}$ and $V_{p, t}$ must be equal or higher than zero.

\section{ILLUSTRATIVE APPLICATION}

The optimization model was applied in a multinational company of the metal-mechanic segment producing durable goods that are supplied to large OEMs. The model was used in a manufacturing plant, located in Brazil, which supplied the European, North American, and Latin American markets (besides Brazil). As described in previous sections, usage of the model follows a sliding window approach - in this illustration the period is monthly and the time horizon considered for each decision is six months ahead. The model is run in the beginning of each month and uses six months of relevant data including demand forecasts and capacity characteristics to inform the decision for the current month.

\subsection{Context of application}

The company had a medium and short-term planning structure very similar to that presented in Figure 1. At the tactical level, an S\&OP process updated 18-month sales forecasts every month. An integrated sales, production, and inventory plan resulted from this process.

\subsubsection{Product hierarchy}

The production aggregation structure of the company had four levels. The highest level was the product family, with products of similar application and technical characteristics. The next level was the subfamily, in which the products are grouped in an application range with higher degrees of specificity. The third level, the model level, was characterized by products with similar physical structures and manufacturing processes. The last level was the SKU. At this level, the product has its final configuration, such as its pallet type and accessories. The company product portfolio was composed of 7 families, divided in 40 subfamilies, 250 models and 1,500 SKUs.

In the company's product hierarchy, the SKU would be equivalent to Hax and Meal's (1975) item level. The model in the company's hierarchy would be equivalent to the family level in Hax and Meal (1975). Their product type level is equivalent to the company's subfamily, in which productive processes, cost structures, and production seasonalities are similar. The company's family level had broader scope, with similarities in costs and productive processes. The S\&OP production plan was developed at the model level and consolidated at the subfamily and family levels. The model level was chosen for two main reasons. First, manufacturing constraints would be impossible to include for an aggregation above the model level. Second, there is very good precision in the contribution margin and variable cost determination at the model level.

\subsubsection{Production process}

The manufacturing structure of the company was organized in component production cells and final assemblies. Each component production cell might use either purchased raw materials or components produced in other production cells. The product assembly lines were at the end of the manufacturing flow, and each of them was supplied by component production cells. There were several supply possibilities for each final assembly, depending on the mix being assembled. Figure 3 presents a simplified process flow for the plant. Raw materials were used to manufacture $2^{\text {nd }}$ level components and these components were then manufactured into $1^{\text {st }}$ level components to be used in final assembly. $1^{\text {st }}$ level components couldn't be stocked due to technical constraints and, as a result, their production plan needed to follow the final assembly production plan. 
Figure 3 - Manufacturing flow.

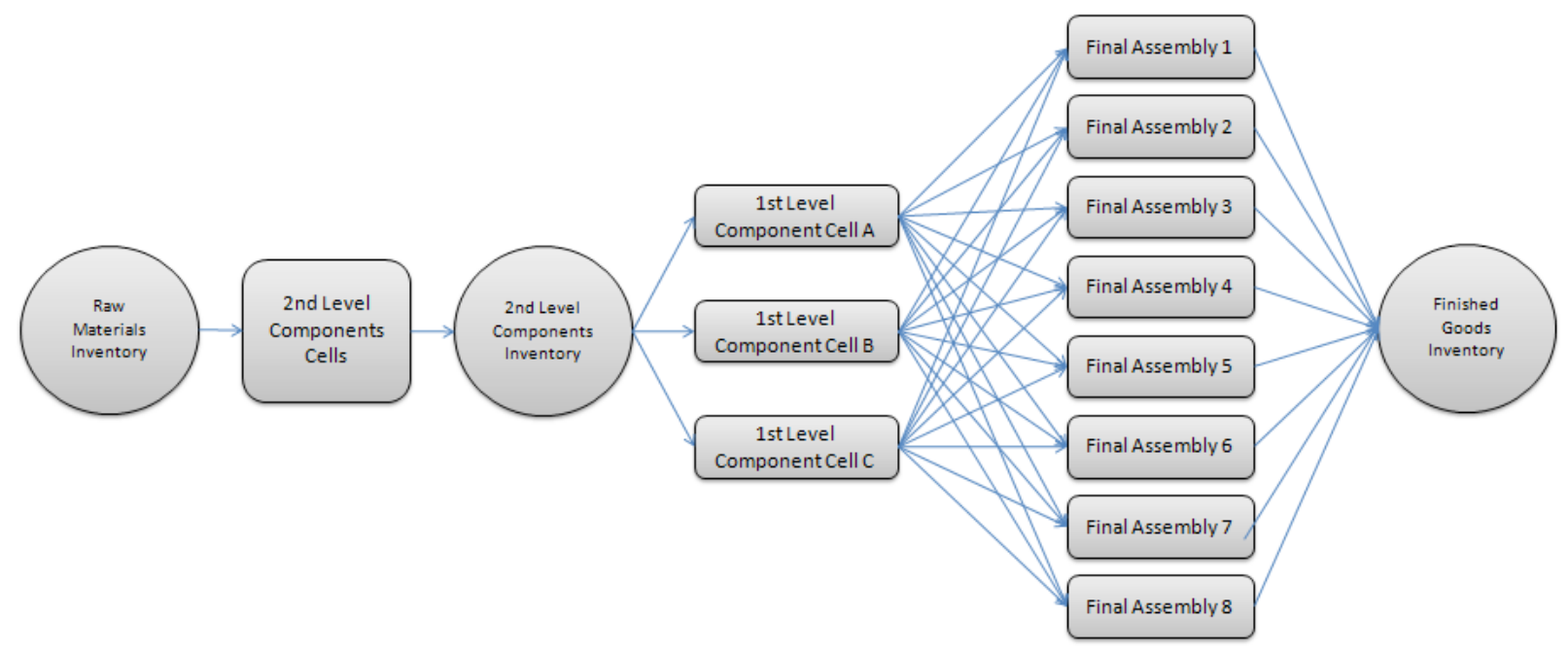

The company had eight final assembly lines and three $1^{\text {st }}$ level component cells. The assembly lines had some differences since each one of them was configured to assemble a certain group of products. The component cells worked with the same logic, as each cell produced a certain group of components. Manufacturing managers had responsibility for continuously implementing improvements to increase line efficiencies (through the elimination of bottlenecks, for example), including periodic capacity increases. In the absence of a holistic view these actions were not necessarily increasing production capacity for the contribution-maximizing product mix.

\subsubsection{Sales and production planning}

The sales and operations planning process begins with a sales forecast, which is updated by the sales force of the company. The sales force is divided in regions for each market segment, each one having a sales manager, who holds main responsibility for the final forecast. The forecast is developed with the help of statistical tools, information obtained from the market and provided by customers, and additional input from the sales force. The aggregation level used is product models per customer. The total forecast of the company is the sum of the forecasts of the market segment/regions. In this illustrative application the production plan is projected for a six month time horizon, considering forecasted sales per customer per model. Costumers are specified because of differences in absolute contribution margins for similar models sold to different clients at different contractual terms.

Table I provides a partial customer/product pairs listing of forecasted sales with contribution margins for the first and sixth time periods ahead. The table further shows a portion of a sales forecast, in which the difference in the contribution margins of a product sold to different customers can be verified. For example, product 172 has a contribution margin of 6.88 when sold to the Client 1 and 44.30 when sold to the Client 71 . The constraints used in the model formulation are: regular and overtime production capacities per assembly line and per first level component cell, the component needs for each model, and demand per model in each period. Total manufacturing capacity has been not enough to fulfill forecasted demand, so the Sales and Operations Planning process also can help resolve conflicts between Sales and Manufacturing. This can best be achieved by balancing demand and available capacity to maximize total contribution to profits, i.e., the optimization criterion should be maximization of company financial results. The result of this process is one single feasible plan for sales and production. 
Table I - Sales forecast example

\begin{tabular}{llrrrrr}
\hline & & T1 & T1 & $\ldots$ & T6 & T6 \\
\hline & & \multicolumn{3}{c}{ Unitary } & & \multicolumn{2}{c}{ Unitary } \\
& & Sales Contribution & & Sales Contribution \\
& & Forecast & Margin & $\ldots$ & Forecast & Margin \\
\hline Customer 1 & Product 153 & 432 & 6.92 & $\ldots$ & 1,524 & 6.92 \\
Customer 1 & Product 170 & 0 & 9.81 & $\ldots$ & 3,201 & 9.81 \\
Customer 1 & Product 172 & 0 & 6.88 & $\ldots$ & 459 & 6.88 \\
Customer 2 & Product 51 & 0 & 27.15 & $\ldots$ & 8,100 & 27.15 \\
Customer 2 & Product 58 & 0 & 5.90 & $\ldots$ & 2,700 & 5.90 \\
Customer 2 & Product 209 & 1,500 & 48.13 & $\ldots$ & 2,100 & 48.13 \\
$\ldots$ & $\ldots$ & $\ldots$ & $\ldots$ & $\ldots$ & $\ldots$ & $\ldots$ \\
Customer 21 & Product 79 & 11,250 & 12.07 & $\ldots$ & 11,250 & 12.07 \\
Customer 21 & Product 105 & 11,250 & 12.07 & $\ldots$ & 7,500 & 12.07 \\
Customer 21 & Product 163 & 5,160 & 12.07 & $\ldots$ & 2,580 & 12.07 \\
Customer 21 & Product 172 & 0 & 12.07 & $\ldots$ & 2,580 & 12.07 \\
Customer 21 & Product 173 & 0 & 12.07 & $\ldots$ & 0 & 12.07 \\
$\ldots$ & $\ldots$ & $\ldots$ & $\ldots$ & $\ldots$ & $\ldots$ & $\ldots$ \\
Customer 71 & Product 81 & 189 & 44.31 & $\ldots$ & 45 & 44.31 \\
Customer 71 & Product 170 & 138 & 44.31 & $\ldots$ & 114 & 44.31 \\
Customer 71 & Product 172 & 300 & 44.31 & $\ldots$ & 423 & 44.31 \\
Customer 71 & Product 173 & 165 & 44.31 & $\ldots$ & 317 & 44.31 \\
$\ldots$ & $\ldots$ & $\ldots$ & $\ldots$ & $\ldots$ & $\ldots$ & $\ldots$ \\
Customer 74 & Product 74 & 450 & 11.73 & $\ldots$ & 219 & 11.73 \\
Customer 74 & Product 77 & 150 & 11.22 & $\ldots$ & 36 & 11.22 \\
Customer 74 & Product 81 & 450 & 11.22 & $\ldots$ & 219 & 11.22 \\
Customer 74 & Product 83 & 4,650 & 11.31 & $\ldots$ & 2,766 & 11.31 \\
Customer 74 & Product 146 & 216 & 11.38 & $\ldots$ & 152 & 11.38 \\
Customer 74 & Product 157 & 324 & 11.57 & $\ldots$ & 212 & 11.57 \\
Customer 74 & Product 158 & 0 & 11.57 & $\ldots$ & 30 & 11.57 \\
Customer 74 & Product 159 & 2,484 & 11.96 & $\ldots$ & 1,971 & 11.96 \\
Customer 74 & Product 161 & 3,996 & 10.42 & $\ldots$ & 2,154 & 10.42 \\
Customer 74 & Product 162 & 1,080 & 10.24 & $\ldots$ & 363 & 10.24 \\
Customer 74 & Product 165 & 2,484 & 12.46 & $\ldots$ & 1,721 & 12.46 \\
Customer 74 & Product 167 & 4,212 & 12.33 & $\ldots$ & 2,016 & 12.33 \\
Customer 74 & Product 170 & 1,188 & 12.19 & $\ldots$ & 455 & 12.19 \\
\hline & & & & & &
\end{tabular}

The conflicts to be resolved with help from SO\&P are usually related to production prioritization choice of customers to be supplied. As manufacturing can do little to improve total capacity in the short/medium term, conflicts are in general resolved within the Sales Force. The prioritization process has traditionally been led by Sales. Each regional manager feeds the S\&OP with the possible changes in their customers' sales projection according to the regional strategy. Often criteria used to choose one customer over another were subjective, e.g., the relationship of the sales manager with the purchaser or the customer without consideration of other sales regions' strategies. If any, the financial criteria used in this prioritization, were generally revenue or volume maximization depending on each regional strategy. The cost of holding inventories or other manufacturing costs were seldom if ever considered at this point of the planning process. 
The S\&OP team verifies possible demand shifts until a feasible plan is reached. They are also responsible for pointing out opportunities missed by Sales and for suggesting manufacturing adjustments given the projections. Despite efforts from the S\&OP function, because of the complexity of the whole process it is difficult to have a clear picture of all the trade-offs involved in the choice of the best product/customer mix without support of a decision-making tool based on objective company-wide criteria.

\subsubsection{Use of the optimization model}

As described, use of an optimization model has the objective of maximizing company performance through the selection of the product/customer mix with the best balance between the contribution margins (price minus variable costs) and operating costs as overtime production costs and inventory holding costs. The model also indicates possible additional gains with the expansion of the production capacity of each analyzed resource, and therefore becomes a tool that can be helpful for long-range planning as well. Figure 4 depicts a simplified flow of the Sales and Production Planning process with use of the optimization model.

Figure 4. Sales and Production Plan Flow

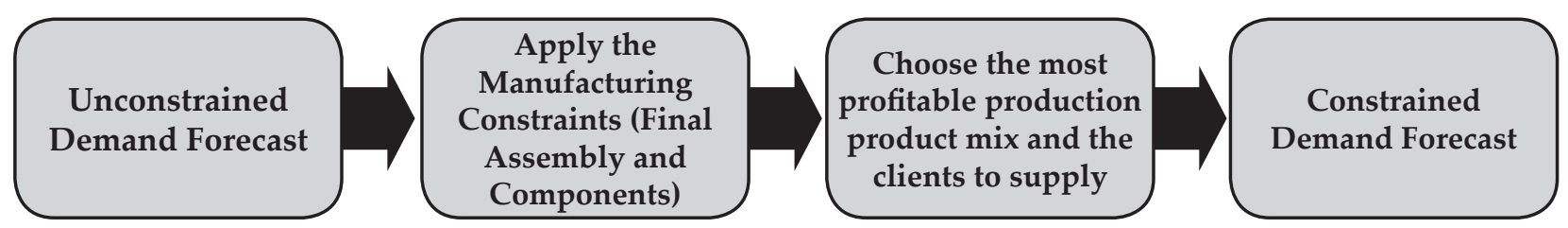

\subsection{Data collection}

The data for the application consists of demand projections per model and per client, regular and over- time capacity available, productivity of each assembly and component line, the company's inventory holding discount rate, the contribution margin per client/model, and costs per product model used.

Table II. Assembly line productivity

\begin{tabular}{lr}
\hline & Productivity \\
\hline Assembly Line 1 & 350 \\
Assembly Line 2 & 350 \\
Assembly Line 3 & 342 \\
Assembly Line 4 & 310 \\
Assembly Line 5 & 380 \\
Assembly Line 6 & 380 \\
Assembly Line 7 & 310 \\
Assembly Line 8 & 360 \\
\hline
\end{tabular}

Table II presents the productivity of each of the assembly lines, in assembled products per hour. In this illustrative example the productivity of each assembly line remains constant over the time horizon in consideration, but the model is robust to changing productivity levels over time.

Table III. Assembly line regular and overtime working hours available

\begin{tabular}{lrrrrrr}
\hline & T1 & T2 & T3 & T4 & T5 & T6 \\
\hline Regular working hours & 516 & 512 & 483 & 553 & 502 & 396 \\
Overtime working hour & 64 & 65 & 60 & 68 & 68 & 45 \\
\hline
\end{tabular}


Table III shows the regular and overtime hours of work available in each time period. In this illustrative example all assembly lines work in the same time schedule in each period but the model is robust to the situation in which different assembly lines have different labor schedules in the same period.

Regular production capacity is the product of the regular labor hours and the productivity of each assembly line, while overtime production capacity is the product of overtime labor hours and the productivity of each assembly line.
Table IV presents the productivity of each $1^{\text {st }}$ level component production cell.

Table IV. Component productivity

\begin{tabular}{lr}
\hline & Productivity \\
\hline Components Production Cell 1 & 985 \\
Components Production Cell 2 & 375 \\
Components Production Cell 3 & 250 \\
\hline
\end{tabular}

Component cell capacity is the product of available hours (regular or overtime) and productivity.

Table V. Total sales demand

\begin{tabular}{lrrrrrr}
\hline & $\mathrm{T} 1$ & $\mathrm{~T} 2$ & $\mathrm{~T} 3$ & $\mathrm{~T} 4$ & $\mathrm{~T} 5$ & $\mathrm{~T} 6$ \\
\hline P1 & 13,278 & 18,270 & 15,743 & 11,952 & 12,965 & 11,805 \\
P2 & 1,944 & - & 2,592 & 2,592 & 2,592 & 2,592 \\
P3 & 6,480 & 9,780 & 13,661 & 10,029 & 15,077 & 9,324 \\
P4 & 224 & 708 & 524 & 525 & 572 & 824 \\
P5 & 49,518 & 71,714 & 136,713 & 139,494 & 137,616 & 127,331 \\
P6 & 126 & 399 & 296 & 297 & 324 & 461 \\
P7 & - & - & 2,592 & 2,592 & 2,592 & 2,592 \\
P8 & 6,815 & 13,845 & 8,046 & 6,480 & 7,661 & 6,098 \\
P9 & 19,764 & 8,154 & 7,443 & 11,019 & 8,252 & 11,492 \\
P10 & - & - & 3,240 & 3,240 & - & - \\
P11 & 7,191 & 47,277 & 64,029 & 80,586 & 82,562 & 62,78 \\
P12 & 10,728 & 13,181 & 8,241 & 2,642 & 6,479 & 6,959 \\
P13 & 22,500 & 22,680 & 38,354 & 38,880 & 43,500 & 42,120 \\
P & $\ldots$ & $\ldots$ & $\ldots$ & $\ldots$ & $\ldots$ & $\ldots$ \\
P205 & 480 & - & 990 & 750 & 750 & 4,050 \\
P206 & 25,947 & 26,256 & 14,232 & 13,388 & 6,933 & 7,142 \\
P207 & 25,275 & 27,821 & 21,471 & 20,658 & 29,435 & 29,174 \\
P208 & 34,032 & 31,790 & 23,070 & 38,445 & 26,703 & 31,704 \\
P209 & 1,500 & - & 2,400 & 2,400 & 2,100 & 2,850 \\
P210 & - & 1,110 & 1,050 & 1,440 & 1,320 & 2,076 \\
P211 & - & - & 675 & 300 & - & 600 \\
P212 & - & 750 & 975 & 1,875 & 1,575 & 900 \\
P213 & - & 1,239 & 68 & 404 & 63 & 330 \\
P214 & - & - & 3,450 & 3,450 & 5,700 & 5,700 \\
P215 & - & 1,050 & 5,400 & 6,225 & 5,850 & 5,850 \\
P216 & - & 150 & 450 & 450 & 450 \\
P217 & - & 6,250 & 6,750 & 2,400 & 3,000 & 8,550 \\
\hline Total sales demand & $1,939,497$ & $1,793,133$ & $2,169,236$ & $1,906,292$ & $1,856,453$ & $2,067,365$ \\
\hline & & & & & &
\end{tabular}

Table $\mathrm{V}$ presents the total monthly sales demand per product for the six-month period.

The initial inventory volume in period T) was 764.824 units. The average contribution margin, weighted by the average volume of the total sales demand, was $\mathrm{R} \$ 13.67$ (the Brazilian Real exchange rate was one US dollar for R\$ 1.80 on September 20, 2009).
Utilization of the model directly impacted company results. Operational profit, return on assets, and cash flow generation all improved substantially as products with a higher contribution margin were prioritized and the lowest storage cost products were held in inventory. The average product/client pair contribution margin weighted by confirmed volume obtained by the model was $\mathrm{R} \$ 17.22$, (fulfilled demand). This represented an improvement of $26 \%$ relative to the average product/client pair contribution margin of unconstrained demand, which is

\subsection{Results}


$\mathrm{R} \$ 13,67$. The average margin of the product/client pair whose demand was not fulfilled by the optimization model was $\mathrm{R} \$ 6.35$.

For each Assembly Line, the model has chosen the product/client mix that maximizes the company's results. Table VI presents a sample of the contribution margin of the fulfilled and unfulfilled demands for a specific product produced in the Assembly Line 3.

Table VI. Realized contribution margin for product 11

\begin{tabular}{llrrrr}
\hline & & Unconstrained & Fulfilled & Unfulfilled \\
& & Unitary Margin & demand* & demand* & demand* $^{*}$ \\
\hline Product 11 & Client 27 & 15.22 & 32,400 & 32,400 & 0 \\
Product 11 & Client 34 & 10.05 & 62,580 & 50,383 & 12,197 \\
Product 11 & Client 40 & 8.72 & 88,580 & 0 & 88,580 \\
Product 11 & Client 52 & 9.71 & 9,122 & 5,882 & 3,240 \\
Product 11 & Client 60 & 17.88 & 87,327 & 87,327 & 0 \\
Product 11 & Client 63 & 11.54 & 64,416 & 64,416 & 0 \\
\hline
\end{tabular}

* For the six-month period

Table VI presents the contribution margins obtained for Product 11, whose demand was partially fulfilled by the model. . In this situation, the difference between unit contribution margins for a product sold to different clients is apparent. The model recommends that Client 40 not be served while clients 34 and 52 be only partially served. Product 11 is assembled in Line 3, which produces products with an average unit contribution margin of $R \$ 13,46$, The model suggests producing for clients with margins below average only in periods in which the projected demand of higher-margin clients is low.

The values of dual variables can be very helpful in interpreting the ramifications of the optimal solution. Three situations are possible: (a) client demand was not fulfilled; (b) client demand was partially fulfilled; and (c) client demand was completely fulfilled. In situation (a), the shadow price or reduced cost (expressions which represent the dual variable, i.e, the change in the objective function achieved with the unit relaxation of a restriction or variable) associated with the non-negativity restriction of the variable representing quantity of a given product for a given client will indicate the change in this product's contribution that is necessary for it to become economically viable. If this product is assembled absent a margin adjustment, the shadow price will inform the net amount that is lost by choosing to assemble the product. On the other hand, when client demand is completely fulfilled, as in situation (c), the dual variable allows for the understanding of gains and losses associated with a unit change in quantity produced. Finally, in situation (b), in which demand is only partially fulfilled, because the variable is in the base of the optimal solution, in order to identify the change in profit contribution from varying the quantity produced for the client, it is necessary to insert another constraint limiting the quantity produced to the optimal amount plus one. The shadow price of this additional constraint represents the unit change in contribution if this product/client pair is attended. Therefore dual variables can be extremely useful to evaluates trade-offs between not fulfilling borderline orders and the fulfilling demand of preferred customers. This analysis can also be useful in price renegotiations to ensure losses are not incurred.

Table VII shows the fulfilled demand and unit contribution margins for product 172 . 
Table VII. Realized contribution margins for product 172

\begin{tabular}{llrrrr}
\hline & & Unitary Margin & $\begin{array}{r}\text { Unconstrained } \\
\text { demand }\end{array}$ & $\begin{array}{r}\text { Fulfilled } \\
\text { demand }^{*}\end{array}$ & $\begin{array}{r}\text { Unfulfilled } \\
\text { demand }^{*}\end{array}$ \\
\hline Product 172 & Client 1 & 6.88 & 2,396 & 0 & 2,396 \\
Product 172 & Client 21 & 12.07 & 5,160 & 0 & 5,160 \\
Product 172 & Client 34 & 12.15 & 2,460 & 0 & 2,460 \\
Product 172 & Client 42 & 16.80 & 4,673 & 4,673 & 0 \\
Product 172 & Client 46 & 26.16 & 204 & 204 & 0 \\
Product 172 & Client 47 & 28.91 & 2,604 & 2,604 & 0 \\
Product 172 & Client 49 & 41.52 & 99 & 99 & 0 \\
Product 172 & Client 56 & 16.77 & 1,253 & 1,253 & 0 \\
Product 172 & Client 65 & 25.29 & 72 & 72 & 0 \\
Product 172 & Client 66 & 33.43 & 6,885 & 6,885 & 0 \\
Product 172 & Client 70 & 34.79 & 9 & 9 & 0 \\
Product 172 & Client 71 & 44.31 & 2,244 & 2,244 & 0 \\
Product 172 & Client 73 & 12.75 & 2,853 & 0 & 2,853 \\
\hline
\end{tabular}

* For the 6 month period

Clients 21, 34, and 73 are not served with Product 172 even though their unit margins are better than the pair Product 11 / Client 63, which had its demand fulfilled. The reason is that Product 172 can be only assembled in Assembly Line 4, which assembles products with an average contribution margin of 17.66. This margin is significantly higher than the average margin of products assembled in Line 3, which assembles Product 11.

Dual variables can be analyzed to evaluate the advisability of outsourcing extra capacity or even of investment in capacity expansion both in fabrication and assembly. In order for temporary outsourcing - for one or few periods - to be worthwhile, the cost of outsourcing such capacity needs to be lower than the dual variable (the shadow price) of the respective restriction. The gain is the difference between the dual variable and the unit cost of outsourcing. When considering capacity expansion it is necessary to examine the project's ROI. In this case the shadow price should be used in the discounted cash flow that is used in the analysis. If the IRR is better than the investor's hurdle rate, the investment in added capacity will make sense.

In this illustrative example, results do not point towards use of overtime because of the low aver- age margins of the unfulfilled product/clients even though the average margin of the products assembled in line L4, geared towards top-of-line models, was $R \$ 17.66$, higher than the average value of all the confirmed products/clients. An improvement in this assembly line's capacity would result in a higher average margin of the company. Sales, production, and inventory levels are reported in Table VIII.

There is an increase in inventory when compared to initial levels, signaling an initial mix of products in inventory without corresponding demand. It also indicates an imbalance between the individual model production capacity and demand. Considering that regular capacity must be utilized, if a specific assembly line's models don't have enough demand in the period, the optimization model will suggest production of models with lower impact on cash flow. Only the cell that produces the component C2 has its entire capacity utilized, resulting in lack of this specific component in the assembly line. However, due to the low margins of the products that use this component, an average of $\mathrm{R} \$ 6.28$, any investment in increasing capacity of this resource would increase the capacity of the company to produce models with lower contribution margins than the current average margin. 
Table VIII. Sales, production and inventory results per time period

\begin{tabular}{|c|c|c|c|c|c|c|c|}
\hline & $\mathrm{T} 0$ & $\mathrm{~T} 1$ & $\mathrm{~T} 2$ & $\mathrm{~T} 3$ & $\mathrm{~T} 4$ & T5 & $\mathrm{T} 6$ \\
\hline Total demand & & $1,939,497$ & $1,793,133$ & $2,169,236$ & $1,906,292$ & $1,856,453$ & $2,067,365$ \\
\hline Unfulfilled demand & & 633,844 & 759,517 & 764,228 & 564,518 & 428,643 & 683,099 \\
\hline Sales & & $1,305,653$ & $1,033,616$ & $1,405,008$ & $1,341,774$ & $1,427,810$ & $1,384,266$ \\
\hline Production & & $1,435,512$ & $1,424,384$ & $1,343,706$ & $1,538,446$ & $1,395,173$ & $1,100,281$ \\
\hline Inventory & 764,824 & 894,683 & $1,285,451$ & $1,226,931$ & $1,423,603$ & $1,390,966$ & $1,106,981$ \\
\hline
\end{tabular}

Table IX shows the impact of the suggested production planning on individual production cells. The only cell at full capacity is cell number 2 .

Table IX. Component Cell Results

\begin{tabular}{llrrrrrr}
\hline & & $\mathrm{T} 1$ & $\mathrm{~T} 2$ & $\mathrm{~T} 3$ & $\mathrm{~T} 4$ & $\mathrm{~T} 5$ & $\mathrm{~T} 6$ \\
\hline Demand & Component Production Cell 1 & 465,750 & 473,300 & 549,638 & 351,141 & 278,772 & 403,716 \\
& Component Production Cell 2 & 394,149 & 440,535 & 509,562 & 315,011 & 222,903 & 368,765 \\
& Component Production Cell 3 & 91,974 & 98,565 & 83,873 & 96,516 & 88,091 & 103,587 \\
Production & Component Production Cell 1 & 262,850 & 261,831 & 211,794 & 235,914 & 232,900 & 174,901 \\
& Component Production Cell 2 & 193,500 & 192,000 & 181,125 & 207,375 & 188,063 & 148,313 \\
& Component Production Cell 3 & 76,785 & 95,430 & 80,784 & 96,267 & 88,091 & 98,800 \\
Total capacity & Component Production Cell 1 & 508,260 & 504,32 & 475,755 & 544,705 & 493,978 & 389,568 \\
& Component Production Cell 2 & 193,500 & 192,000 & 181,125 & 207,375 & 188,063 & 148,313 \\
& Component Production Cell 3 & 129,000 & 128,000 & 120,75 & 138,25 & 125,375 & 98,875 \\
Unfulfilled demand & Component Production Cell 1 & 202,900 & 211,469 & 337,844 & 115,227 & 45,873 & 228,816 \\
& Component Production Cell 2 & 200,649 & 248,535 & 328,437 & 107,636 & 34,841 & 220,452 \\
& Component Production Cell 3 & 15,189 & 3,135 & 3,089 & 249 & 0 & 4,787 \\
Idle capacity & Component Production Cell 1 & 245,410 & 242,489 & 263,961 & 308,791 & 261,078 & 214,667 \\
& Component Production Cell 2 & 0 & 0 & 0 & 0 & 0 & 0 \\
& Component Production Cell 3 & 52,215 & 32,57 & 39,966 & 41,983 & 37,284 & 75 \\
\hline
\end{tabular}

\section{DISCUSSION}

The most important result of the use of this methodology was that it became a vector for increased dialogue among different functional areas of the firm. Use of the optimization model sheds light on the company's marketing, sales, and operational performance indicators, especially those related to the delivery of goods. The model also becomes a tool for long term planning in that resources committed to capacity increases are allocated in a way that maximizes overall performance levels.

Previously the sales planning process had resulted from several fragmented decisions in which individual product/client pair contribution margins were taken into account, but in the absence of comprehensive comparisons with all other feasible product/ client pair alternatives. Use of the model leads to increased dialogue between the sales and manufacturing areas, not only because all parties have to agree on input parameters, but also because all parties address additional questions and alternatives regarding specific product/client pairs. Use of the methodology also increases dialogue between separate sales geographical regions because the tradeoffs involved in different sales alternatives are more clearly understood.

The methodology also helps strengthen ties between Marketing and Manufacturing, between Marketing and Product Design, and between Marketing and Sales. Use of the model increases sensitivity to the importance of the overall portfolio of products and helps prioritize product design initiatives that could offer the best return with the least disruption to the manufacturing process. Use of the model also becomes a vehicle for improved client management through several initiatives, such as adjusting margins of certain clients upward, offering differentiated services to clients with higher contributions, promoting certain products from lines not used to capacity, and prospecting new clients with product needs that correspond to the highest possible contribution to profits.

Additionally, use of the methodology helps increase distribution efficiency and tightens the links between the logistics functions, and Marketing, and Manufacturing. Special logistics services, such as preferred delivery, can be offered to the best clients. Furthermore, the warehousing of products is im- 
proved, as the logistics network is adjusted to reflect the relative importance of individual product lines. Delivery reliability also increases as the model takes into account all system constraints.

More specifically, use of the optimization model brings intangible benefits to the management of the client/product mix. Figure 5 presents a matrix which correlates the average contribution margin and the sales volume per client/product pairing during the analysis period.

Quadrant "A" represents SKUs with volumes above 15,000 units and a contribution margin higher than $\mathrm{R} \$ 25.00$ during the period of analysis. Quadrant " $\mathrm{B}$ " represents SKUs with volume above 15,000 units and contribution margin under R $\$ 25.00$. Quadrant "C" represents SKUs with margins above $\mathrm{R} \$ 25.00$ and volumes under 15,000 units. Quadrant " $\mathrm{D}$ " represents SKUs with margins and the volumes under those limits. Table $X$ presents the hypothetical situation in which all demand is met and products manufactured are classified in one of the four categories described above.

\section{Figure 5. Contribution margin and sales volume}

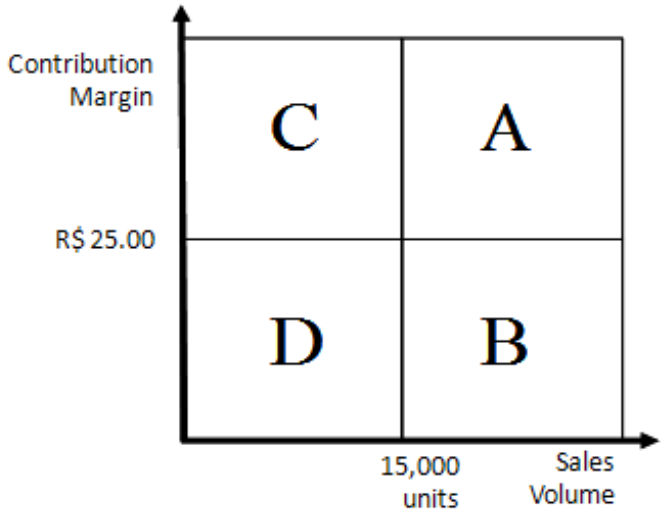

Under the assumption that all demand can be met, i.e., without use of the methodology, $24 \%$ of the SKUs were classified as either " $\mathrm{A}$ " or " $\mathrm{B}$ " and accounted for $83 \%$ of company earnings. Although average class " $\mathrm{B}$ " margins weighted by volumes were lower, aggregate earnings were higher than those of classes " $\mathrm{C}$ " and " $\mathrm{D}$ " due to higher volumes. As an alternative strategy, there could be a sales and marketing effort to increase volumes of class " $\mathrm{C}$ " items, leading to an increase in total company earnings. The question becomes which products to prioritize when there is a constraint on the demand to be met. This discussion is an example of the strategic impact of an informative S\&OP process on other functional areas in the firm and illustrates the power of this integrated methodology.

Table X. Classification of the SKUs when all demand is met

\begin{tabular}{lrrrrrr}
\hline & \multicolumn{5}{c}{ Weighted average } & Average earning \\
Classification & Nr. of SKUs & \% SKUs & margin & by SKU & Total earnings & \% Earning \\
\hline A & 23 & $4 \%$ & 31.55 & $1,368,153.55$ & $31,467,531.64$ & $20 \%$ \\
B & 127 & $20 \%$ & 11.00 & $801,660.28$ & $101,810,856.02$ & $63 \%$ \\
C & 194 & $31 \%$ & 31.36 & $60,148.09$ & $11,668,728.96$ & $7 \%$ \\
D & 286 & $45 \%$ & 13.82 & $53,851.41$ & $15,401,502.30$ & $10 \%$ \\
\hline
\end{tabular}

With the application of the methodology with constrained demand, 77 SKUs were selected to not be produced at all, 45 of which were in quadrant " $\mathrm{D}$ ", and 32 of which were in quadrant " $\mathrm{B}$ " - the methodology prioritized " $C$ " SKUs over "B" SKUs because the main optimization criterion was contribution to profits. 30 SKUs have their demand only partially fulfilled, 4 of which were class " $\mathrm{B}$ " and 26 of which were class " $\mathrm{D}$ ". The very existence of production selections for class " $\mathrm{B}$ " and class " $\mathrm{D}$ " SKUs in this illustration is a result of the desirability to more fully utilize manufacturing line capacity, i.e., if there is not sufficient demand to fully use assembly lines with other product models, SKUs with lowest contribution margins will also be assembled. Table XI presents the classification by sales volume/contribution margin of the SKUs selected in the illustrative application. In this case, $21 \%$ of SKUs are responsible for $82 \%$ of earnings.

The weighted average margin increased in classes " $\mathrm{B}$ ", " $\mathrm{C}$ " and " $\mathrm{D}$ " with the selection of the respective methodology SKUs. For example, in class "B", the margin went from $\mathrm{R} \$ 11.00$ to $\mathrm{R} \$ 14.15$, an increase of $29 \%$. Again, this finding can be used to support 
the company's marketing strategy. For example, from the analysis of the results, several marketing suggestions and analyses are possible, such as verifying the appropriateness of increasing volume of " $\mathrm{C}$ " items, of increasing prices of " $\mathrm{B}$ " items, and examining the possibility of migrating " $\mathrm{D}$ " items to other quadrants or, absent other strategic reasons to produce them, to have them discontinued. This kind of analysis must be made focusing on strategic determinants that are not included in the quantitative analysis, such as the importance of the clients and the development of new markets.

Table XI. Classification of SKUs in the illustration

\begin{tabular}{lrrrrrr}
\hline & \multicolumn{5}{c}{ Weighted average } & Average earning \\
Classification & Nr. of SKUs & \% SKUs & margin & by SKU & Total earnings & \% Earning \\
\hline A & 23 & $4 \%$ & 31.55 & $1,368,171.96$ & $31,467,955.11$ & $23 \%$ \\
B & 95 & $17 \%$ & 14.15 & $842,875.50$ & $80,073,267.61$ & $59 \%$ \\
C & 194 & $35 \%$ & 32.06 & $60,180.18$ & $11,674,954.04$ & $9 \%$ \\
D & 241 & $44 \%$ & 14.58 & $53,072.37$ & $12,790,440.65$ & $9 \%$ \\
\hline
\end{tabular}

Turning to individual client and product model analysis, 4 of the 74 clients were not serviced, i.e., no products were assembled for them. 12 of the 74 clients, or $16 \%$ of the total client portfolio had less than $25 \%$ of their demand serviced. On the product side, 2 product models were not produced 37 had less than $25 \%$ of their demand produced. The elimination of these products would represent an $18 \%$ reduction in the product portfolio resulting in more streamlined operations.

\section{CONCLUSION}

The use of the methodology presented herein gives complete visibility of the client/product combinations that offer highest return in each tactical planning cycle, given market demand and operational constraints. This is a powerful tool to help manufacturing, marketing, and sales functions and helps increase communication among those functions. Use of the optimization model in an integrated way can provide support for marketing strategies, directing efforts to prioritize more profitable clients and products and to reduce focus on less profitable client/ product combinations. It is possible to include nonfinancial marketing data, such as individual client seasonality (or lack thereof) to help identify the best long-term client relationships. Accounts receivable payment lags and consequent impact on cash flows can be included to help identify best product/client pairs. The model can also be useful for product development, as it identifies better margin products and production lines with higher demand products. The lines which produce the products with the lowest demands or margins could absorb new products and thus improve the company's sales mix. Furthermore, this methodology can identify the manufac- turing resources that constrain sales of products to clients whose profitability contribute positively to the results of the company therefore helping prioritize capital investments. In short, the model supports decision-making in various functional areas of the firm.

The model's impact is maximized when it is used in a rolling horizon approach through which decisions are made for one period by incorporating projected data from six to twelve periods ahead into the analysis. This procedure is repeated for each period and allows for the incorporation of medium-term trends into short-term decisions. The paper illustrated use of the model in a Brazilian durable goods manufacturer. Use of the methodology and the resulting increased cross-functional dialogue led to the rationalization of the product/client mix, with increased focus on the most attractive opportunities. Sales and operations planning processes were simplified with this mix rationalization.

The model can also be used as a simulation tool helping test the implementation of different manufacturing configurations, for example through the analysis of different productivity and capacity scenarios. Simulations can also be used for new product feasibility analysis by testing volumes and margins in production planning and taking into account the relevant manufacturing constraints. The utilization of a structured process with well-defined rules ensures control over improvement needs, systematizes analytical decision processes, and helps other areas of the company deepen their understanding of the planning process and its inevitable tradeoffs.

As stated in the introduction, this paper offers several contributions to the literature. The first is to of- 
fer a tool that not only helps integrate different functional areas of the firm, but also helps bridge longterm strategic objectives with short-term shop-floor requirements. The second is to use pricing as well as costing information to obtain individual product contributions to profit and use it (as opposed to the sole consideration of product costs) as a decision variable when capacity is (at least periodically) constrained, resulting in a methodology that is more closely aligned with overall company objectives. The third contribution is the development of a conceptual framework to analyze different product/client pairs and identify those that are most and least profitable. Finally, the paper illustrates the methodology introduced herein with the case of an OEM supplier in Brazil.

\section{REFERENCES}

Anderson, J.C., Cleveland, G., and Schroeder, R. (1989), Operations strategy: A literature review. Journal of Operations Management, 16(4), 341-359.

Axsater, S. (1986), On the feasibility of aggregate production plans. Operations Research, 34(5), 796-801.

Bitran, G.R., Haas, E.A., and A. C. Hax., (1981), Hierarchical production planning: A single stage system. Operations Research, 29(4), 717-743.

Bitran, G.R., Haas, E.A., and A. C. Hax. (1982), Hierarchical production planning: A two-stage system. Operations Research, 30(2), 232-251.

Boyer, K.K., Swink, M. and Roisenzweig, E.D. (2005), Operations strategy research in the POMS journal. Production and Operations Management, 14(4), 442-449.

Crittenden, V.L. and Crittenden, W.F. (1995), Examining the impact of manufacturing and marketing capacity decisions on firm profitability. International Journal of Production Economics, $40,57-72$.

Crittenden, V.L., Gardiner, L.R., and Stam, A. (1993), Reducing conflict between marketing and manufacturing. Industrial Marketing Management, 22, 299-309.

Dempster, M.A.H., Fisher, M.L., Jansen, L., Lageweg, B.J., Lenstra, J.K., and Rinnooy Kan, A.H.G. (1981), Analytical evaluation of hierarchical planning systems. Operations Research, 29(4), 707-716.

Feng, Y., D'Amours, S., and Beauregard, R. (2008), The value of sales and operations planning in oriented strand board industry with make-to-order manufacturing system: Crossfunctional integration under deterministic demand and spot market recourse. International Journal of Production Economics, 115(1), 189-209.

Gianesi, I.G.N. (1998), Implementing manufacturing strategy through strategic production planning. International Journal of Operations \& Production Management, 18(3), 286-299.
Goldratt, E.M. (1988), Computerized shop floor scheduling. International Journal of Production Research, 26(3), 443-455.

Grimson, J.A. and Pyke, D.F. (2007), Sales and operations planning: an exploratory study and framework. International Journal of Logistics Management, 18(3), 322-346.

Hasuike, T. and Ishii, H. (2009), On flexible product-mix decision problems under randomness and fuzziness. Omega, 37, 770-787.

Hausman, H.W., Montgomery, D.B., and Roth, A.V. (2002), Why should marketing and manufacturing work together? Some exploratory empirical results. Journal of Operations Management, 20, 241-257.

Hax, A.C. and Meal, H.C. (1975), Hierarchical Integration of Production Planning and Scheduling. Studies in Management Sciences, Vol. I. New York: North Holland-American Elsevier.

Hayes, R.H. and Pisano, G.P. (1996), Manufacturing strategy: At the intersection of two paradigm shifts. Production and Operations Management, 5(1), 25-41.

Hayes, R.H., Pisano, G.P., Upton, D.M., and Wheelwright, S.C. (2004), Operations, Strategy, and Technology: Pursuing the Competitive Edge. New York: Wiley.

Hayes, R.H. and Wheelwright, S.C. (1984), Restoring our Competitive Edge: Competing through Manufacturing. New York: John Wiley and Sons.

Hayes, R.H.,Wheelwright, S.C., and Clark, K. (1988), Dynamic Manufacturing: Creating the Learning Organization. New York: The Free Press.

Holt, C.C., Modigliani, F., and Simon, H.A. (1956), Derivation of a linear decision rule for production and employment. Management Science, 2(1), 159-177.

Langerak, F. and Hultink, E.J. (2005), The impact of new product development acceleration approaches on speed and profitability: Lessons for pioneers and fast followers. IEEE Transactions on Engineering Management, 52, 30-42.

Lee, W.B. and Khumawala, B.M. (1974), Simulation testing of aggregate production planning models in an implementation methodology. Management Science, 20(6), 903-911.

Ketokivi, M. (2006), Elaborating the contingency theory of organizations: The case of manufacturing flexibility strategies. Production and Operations Management, 15(2), 215-228.

Matuyama, K., Sumita, T., and Wakayama, D. (2009), Periodic forecast and feedback to maintain target inventory level. International Journal of Production Economics, 118, 298-304.

Nazari-Shirkouhi, S., Eivazy, H., Ghodsi, R., Rezaie, K., and Atashpaz-Gargari, E. (2010), Solving the integrated product mix-outsourcing problem using the Imperialist Competitive Algorithm. Expert Systems with Applications, 37, 7615-7626.

Newman, A. M. and Kutchta, M. (2007), Using aggregation to optimize long-term production planning at an underground mine. European Journal of Operational Research, 176, 1205-1218.

Olhager, J. and Rudberg, M. (2002), Linking manufacturing strategy decisions on process choice with manufacturing plan- 
ning and control systems. International Journal of Production Research, 40(10), 2335-2351.

Olhager, J. and Selldin, E. (2007), Manufacturing planning and control approaches: market alignment and performance. International Journal of Production Research, 45(6), 1469-1484.

Özdamar, L., Bozyel, M.A., and Birbil, S.I. (1998), A hierarchical decision support system for production planning (with case study). European Journal of Operational Research, 104, 403-422.

Rao, U.S., Swaminathan, J.M., and Zhang, J. (2005), Demand and production management with uniform guaranteed lead time. Production and Operations Management, 14(4), 400-412.

Singhal, J. and Singhal, K. (2007), Holt, Modigliani, Muth, and Simon's work and its role in the renaissance and evolution of operations management. Journal of Operations Management, $25,300-309$.

Skinner, W. (1985), Manufacturing, the Formidable Competitive Weapon. New York: John Wiley \& Sons.

Sprague, L.G., Ritzman, L.P., and Krajewski, L. (1990), Production planning, inventory management and scheduling: Spanning the boundaries. Managerial and Decision Economics, 11(5), 297-315.
Swamidass, P. M. (1986), Manufacturing strategy: Its assessment and practice. Journal of Operations Management, 14(4), 400412.

Tsoulos, I.G. and Vasant, P. (2009), Product mix selection using an evolutionary technique. Proceedings of the 2009 American Institute of Physics Conference , 159 (1), 240-247.

Vollman, T.E., Berry, W.E., and Whybark, D.C. (1997), Manufacturing Planning and Control Systems. New York: McGrawHill.

Wallace, T.F. (1999), Sales \& Operations Planning - The How-To Handbook. T.F. Wallace \& Company.

Wang, J.Q., Sun, S.D., Si, S.B., and Yang, H.A. (2009), Theory of constraints product mix optimization based on immune algorithm. International Journal of Production Research, 47(16) 4521-4543.

Warburton, R.D.H. (2004), An analytical investigation of the bullwhip effect. Production and Operations Management, 13(2), 150-160.Zhang, Q. and Tseng, M.M. (2009), Modeling and integration of customer flexibility in the order commitment process for high mix low volume production. International Journal of Production Research, 47(22), 6397-6416.

\section{AUTHOR'S BIOGRAPHY}

João Neiva de Figueiredo holds a Ph.D. degree in Business Economics and a Master of Arts degree in Economics from Harvard University, a Master of Business Administration with high distinction from the Harvard Business School, and a Master of Sciences degree in Systems Engineering and Computer Science from COPPE/UFRJ. He currently is on the faculty of Saint Joseph's University in Philadelphia. His research interests include operations strategy, optimization, and sustainability.

Sérgio Fernando Mayerle holds a Doctorate in Production Engineering and a Master of Sciences degree in Production Engineering with emphasis on Operations Research from the Federal University of Santa Catarina. He currently is Associate Professor in the Production and Systems Engineering Department at the Federal University of Santa Catarina. His research interests involve supply chain management, logistics modeling, and optimization algorithms.

Felipe A. Simas Donato holds a Master of Sciences degree in Production Engineering from the Federal University of Santa Catarina. He is currently a consultant at a strategic consulting firm. His research interests involve supply chain management and optimization models. 